\title{
Use of the International Classification of Functioning, Disability and Health in Speech-Language-Hearing Therapy: an integrative literature review
}

\author{
Alice Prado de Azevedo Antunes \\ https://orcid.org/0000-0003-1650-517X \\ Caroline Santos Rodrigues da Silva \\ https://orcid.org/0000-0003-1455-4509 \\ Léslie Piccolotto Ferreira \\ https://orcid.org/0000-0002-3230-7248 \\ Ruth Ramalho Ruivo Palladino \\ https://orcid.org/0000-0001-8466-838X
}

Pontifícia Universidade Católica de São Paulo, São Paulo, São Paulo, Brasil. Research support source: Coordination for the Improvement of Higher Education Personnel (CAPES, from the acronym in Portuguese).

Conflict of interests: Nonexistent

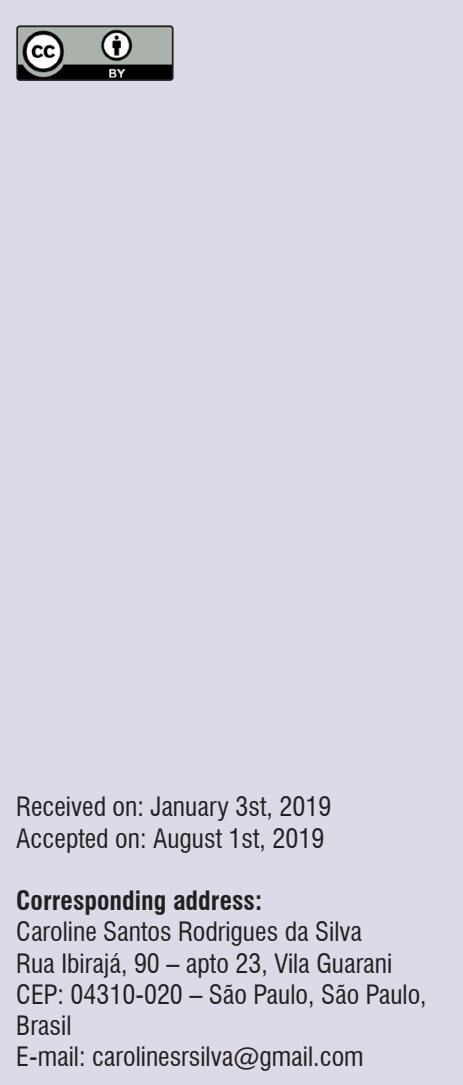

\section{ABSTRACT}

Purpose: to carry out an integrative review of literature regarding the use of the ICF in Speech-Language-Hearing Therapy.

Methods: a search was conducted on both national and international databases, for articles published between 2008 and 2018, considering the following descriptors in Portuguese, English and Spanish: "International Classification of Functioning, Disability and Health", "Speech-Language-Hearing", and "Speech Therapy". Duplicated articles, as well as those introducing new ICF-based protocols and studies whose theme didn't refer exclusively to speech-language-hearing practices were excluded.

Results: 36 articles were found, 9 of which met the inclusion criteria. The articles were categorized according to speech-language-hearing subareas (most belonging to the subarea of language), and to types of study (most being case studies).

Conclusion: studies point out that the ICF can contribute to the development of unique therapy projects in a broader approach to health in the speech-language-hearing clinic. However, it has been perceived the need for more researches on the theme with applicability to the other fields of knowledge in speech-language-hearing sciences.

Keywords: International Classification of Functioning, Disability and Health; Speech Therapy; Speech-Language-Hearing Sciences 


\section{INTRODUCTION}

The interest for the concepts of disability and functioning has been increasing in the health fields. With the medical and technological advances, many diseases have become treatable, causing an increase in life expectancy and, consequently, the emergence of limitations imposed by health condition'.

In 2001, the World Health Organization (WHO) developed the International Classification of Functioning, Disability and Health (ICF), a tool aimed at providing a unified language for pointing out the functioning and disability conditions in individuals, identifying the existing relations between social conditions and health? ${ }^{2}$.

Seeking to broaden the perspective beyond the classification of illnesses, which is offered by the International Classification of Diseases (ICD), the ICF considers that functioning includes all functions of the body, activities and social participation, while the disability encompasses the deficiencies and limitations each person has in the same context ${ }^{3}$. It's an instrument based on a conceptual model which considers the existence of biopsychosocial influences on the health and illness condition ${ }^{2,4}$.

The WHO recommends the use of the ICF as a classification capable of furnishing a statistical standard regarding health and disability and promoting participation, inclusion and health of people with disability, associated with public policy ${ }^{2,5}$. Such classification is done individually, so that people with the same primary illness may be differently classified in the ICF. For instance, two patients may present swallowing disorders, one of them being instructed to receive nutrition and hydration only through alternative feeding, while the other may be told to receive creamy foods orally. In such case, regarding the illness (ICD) both are classified as having Dysphagia; however, in terms of functioning, they have distinct classification in the ICF.

In spite of the complexity of this classification, its use helps professionals to understand their patients' limitations and potentials, in addition to directing the therapeutic intervention $n^{4,6,7}$.

The model and the set of items presented by the ICF guide individual answers regarding health and functioning. Notes may be taken by relatives or health professionals; however, the WHO suggests that the patient be involved in the classification for it to be valid, as well as for ethical reasons ${ }^{2}$.

Aware of the concepts described above, and of the growing interest of health professionals in using the ICF in their procedures ${ }^{8-10}$, this study aims to carry out an integrative review of literature in order to investigate the use of the ICF in speech-language-hearing therapeutic practice.

\section{METHODS}

This study is an integrative review of literature about the use of the ICF in speech-language-hearing therapeutic practice.

As a guideline in searching for literature, the following question was developed: "How is the ICF used in the field of speech-language-hearing?".

The search was conducted in the following databases: Literature in the Health Sciences in Latin America and the Caribbean (LILACS), Medical Literature Analysis and Retrieval System Online (MEDLINE), the United States National Library of Medicine of the National Institutes of Health (PubMed) and the Scientific Electronic Library Online (SciELO).

The Health Sciences Descriptors (DeCS, as abbreviated in Portuguese) used for finding articles, limiting the language to English, Spanish and Portuguese, were: "International Classification of Functioning, Disability and Health", "speech-language-hearing", and "Speech Therapy". The search was conducted by combinations of two associated descriptors (e/and/y).

The initial inclusion criteria were: unprecedented articles, available with full text, published in scientific periodicals in Portuguese, English or Spanish, throughout the past five years, which describe the applicability of the ICF in speech-language-hearing therapeutic practice. Due to the small amount of publications, it was decided to lengthen the period of time to the last ten years, from January, 2008 to August, 2018.

The exclusion criteria were: articles duplicated or introducing new ICF-based protocols, as well as studies whose theme didn't refer exclusively to speechlanguage-hearing practices.

The publications were selected according to these steps: searching for studies in the databases with the combined descriptors; selecting the material published in the predefined period; reading the title and summary in search of studies related to this study's theme; Applying the inclusion and exclusion criteria; thoroughly reading the selected material; and applying the inclusion and exclusion criteria.

All the articles were categorized according to the subareas of speech-language-hearing and to the type of study. 


\section{LITERATURE REVIEW}

The methodology used in this process resulted in 36 articles being found. After the inclusion and exclusion criteria were applied, nine were chosen for this review and thus categorized according to the fields of knowledge in speech-language-hearing, as shown on Figure 1, in which they are presented in the respective subarea of speech-language-hearing and type of research.

The description of the studies included in this review appears on Figure 2.

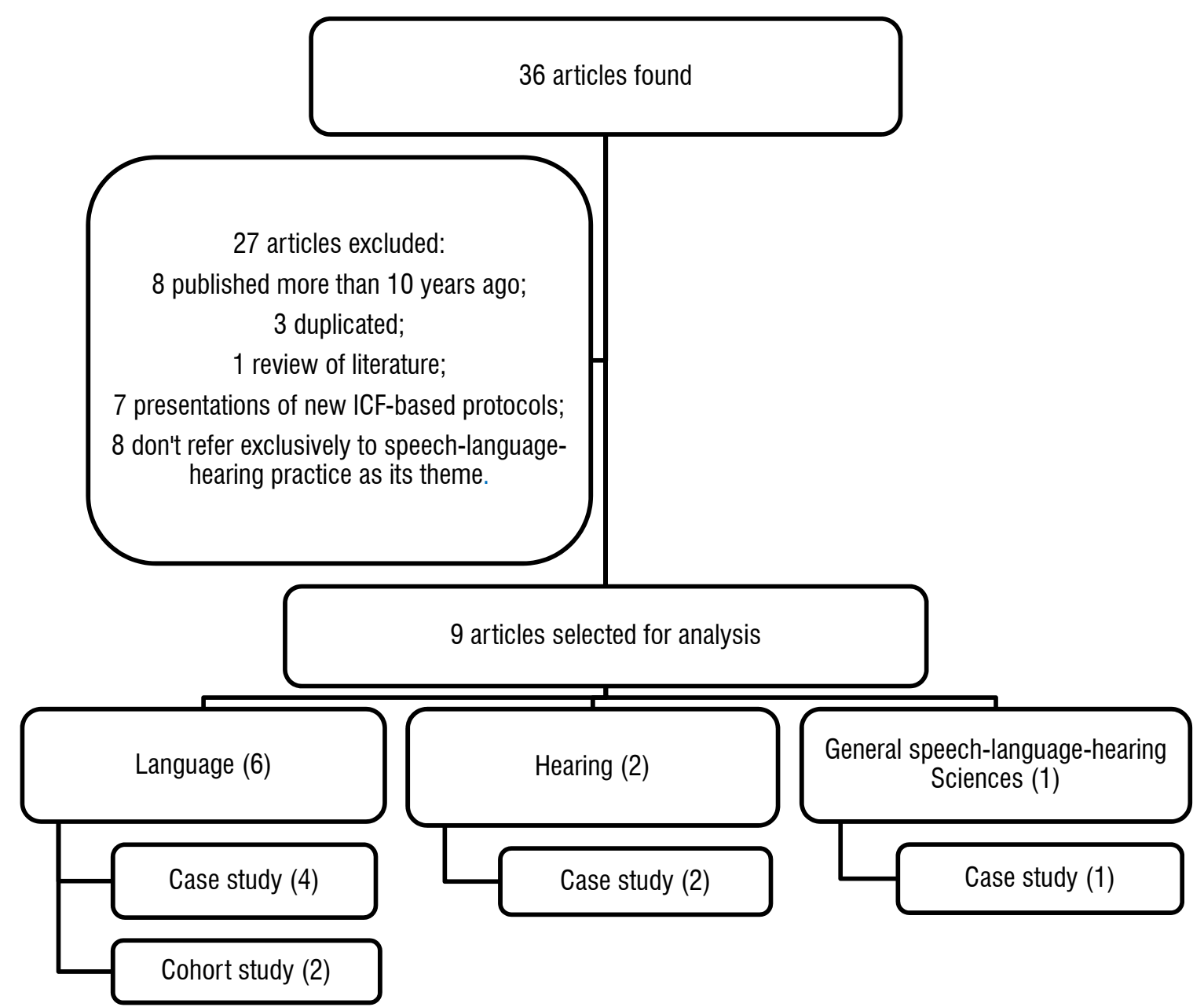

Figure 1. Presentation of the studies selection process, fields of knowledge and types of study 


\begin{tabular}{|c|c|c|c|c|c|}
\hline Year & Author & $\begin{array}{c}\text { Country of } \\
\text { Origin }\end{array}$ & Periodical & $\begin{array}{c}\text { Subarea of Speech- } \\
\text { Language-Hearing }\end{array}$ & Type of Study \\
\hline 2009 & ${\text { Thomas-Stonell et al. }{ }^{11}}^{\text {Journal of }}$ & Canada & $\begin{array}{c}\text { Communication } \\
\text { Disorders }\end{array}$ & Language & Cohort Study \\
\hline 2009 & Stocks et al. $^{12}$ & Australia & Brain Injury & Language & Case Study \\
\hline 2013 & ${\text { Morettin et al. }{ }^{16}}^{2}$ & Brazil & Codas & Hearing & Case Study \\
\hline 2014 & Romano e Chun $^{7}$ & Brazil & $\begin{array}{c}\text { Communication } \\
\text { Disorders }\end{array}$ & Language & Case Study \\
\hline 2016 & Pommerehn, Delboni e $_{\text {Fedosse }}^{14}$ & Brazil & Codas & Language & Case Study \\
\hline 2017 & Ostrochi, Zanolli e Chun $^{13}$ & Brazil & Codas & Language & Case Study \\
\hline 2017 & Santana e Chun $^{15}$ & Brazil & Codas & Language & Cohort Study \\
\hline 2017 & Bernardi et al. $^{17}$ & Brazil & Journal CEFAC & Hearing & Case Study \\
\hline 2018 & Borges, Medeiros e Lemos ${ }^{18}$ & Brazil & Codas & $\begin{array}{c}\text { General Speech- } \\
\text { Language-Hearing } \\
\text { Sciences }\end{array}$ & Case Study \\
\hline
\end{tabular}

Figure 2. Presentation of the articles by year of publication, author(s), country of origin, periodical, subarea of speech-language- hearing, and type of study

In face of the literature produced from January, 2008 to August, 2018, it is observed that the theme of ICF in speech-language-hearing is still little developed. The greatest amount of publications are from 2017 $(n=4)$, and the field of language was the one that presented most publications on the theme $(n=6)$. It was also possible to identify that more case studies were produced $(n=7)$. The contribution of Brazilian researchers $(n=7)$ corresponds to the majority of selected articles.

In the field of language, Thomas-Stonell et al. (2009) ${ }^{11}$ assessed the impact of speech therapy in children, based on the domains of the ICF. It is a longitudinal study carried out with 210 children aged 2 to 6 years, with language disorders. The progress of the therapy was conducted along with the parents' and the speech-language pathologists' perception. The domains of the ICF were used to trace the qualitative evolution of the children after the speech-language therapy.

Stocks et al. (2009) ${ }^{12}$ examined the effects of an intensive speech therapy technique of an adult subject with ataxic dysarthria, including the levels of functioning through the ICF domains. There were evaluations prior and posterior to therapeutic intervention, the ICF being applied in both circumstances. It was possible to perceive an improvement of the patient's functioning after the intervention.

By means of the ICF components, Romano and Chun $(2014)^{7}$ investigated language, participation and performance/functioning issues in children using augmentative and alternative communication (AAC) in linguistic-cognitive activities. It's a longitudinal study with three AAC-using children who couldn't communicate orally, undergoing speech-language-hearing treatment. All the children presented change in the linguistic-cognitive, participation and performance/ functioning conditions after the period of evaluation and speech-language-hearing therapy. The use of the ICF enabled, with time, the verification of a decrease in the level of seriousness or in the barrier that changes in language represented to these children.

Pommerehn et al. (2016) ${ }^{13}$ characterized the living and health conditions of 12 subjects neurologically diagnosed with aphasia. Participants were from both genders, aged 34 to 69 years, and attended the same group, called Interdisciplinary Social Interaction Group. The evaluation process was carried out by a single evaluator, in up to three sessions lasting approximately 40 minutes each, from October, 2011 to March, 2013. The data was collected and analyzed based on the ICF domains. The use of this tool made it possible to identify that all subjects were restricted in their performance and participation in daily activities, due to biological, environmental or sociocultural factors. Restriction in participation was the most evident, mostly resulting from environmental factors, rather than sequelae of brain injury. Thus, the ICF helped understand the impact of the illness on the participants' survival. 
Ostrochi et al. (2017) ${ }^{14}$ carried out a study with 24 children and adolescents in speech-language-hearing treatment due to language disorders. Two sources of data were used: survey of the patients' medical record, and interview with their relatives. Each relative answered a semi-structured interview. Afterwards, a descriptive analysis of the participants' profile was conducted, as well as the categorization of the answers, using the children and youth version of the ICF (ICF-CY). The findings revealed a broadened view of the families towards alterations in speech and language, under a more encompassing health approach. The results reinforce the importance of using the ICF-CY, as it incorporates aspects of functioning and participation, providing the means for the development of unique therapeutic projects.

Santana and Chun $(2017)^{15}$ used the domains of the ICF to assess language, participation and functioning in 50 persons, aged 32 to 88 years, diagnosed with cerebrovascular accident (CVA). The use of the ICF made possible the understanding of language disorders beyond the organic dimension, including social and affective aspects, contributed to a better comprehension of these people's functioning and participation. The results led to a reflection on the impact of the language difficulties on the subjects' post-CVA life, in addition to reaffirming the applicability of the ICF as an important complementary instrument in evaluating language in a wholesome and humanized approach.

In the field of hearing, two studies were registered in this review. Morettin et al. (2013) ${ }^{16}$ characterized the profile of patients with cochlear implant as proposed by the ICF-CY. Thirty medical records of patients with cochlear implant, aged 3 to 18 years, were considered for the analysis, conducted according with the domains of the ICF-CY. In the end, the perspective regarding development and quality of life of children using cochlear implant was broadened, and the authors state that the use of the ICF may help the health professional in planning the therapy and choosing the assessment instruments.

Bernardi et al. (2017) ${ }^{17}$ used the ICF-CY in a healthcare center of the Unified Health System, in the interior of the state of São Paulo, for registering auditory and language development of children in their first year of life. The first stage of the study consisted of training 13 community health agents (ACS, as abbreviated in Portuguese) for them to apply a questionnaire that would monitor auditory and language development in families cared for by the Family Health Strategy. The ACS used the questionnaire with 22 families, corresponding approximately to $5 \%$ of the children from 0 to 1 year old registered in the area covered by this healthcare center. Subsequently, three speech-language-hearing pathologists, specialized in Audiology, conducted the correlation of each of the questions in the questionnaire with the domains of the ICF-CY. Due to the complexity of applying the ICF, a check-list was developed using the ICF-CY codes related to those questions. The checklist went through a content validation process, making its application reliable. Pairing the used instrument with the ICF enabled the identification of three children at risk of auditory alteration. In spite of this study having approached both auditory and language development, it was classified in the "hearing" subarea, as this was the main focus throughout the article.

Classified as General Speech-Language-Hearing Sciences, the study proposed by Borges et al. (2018) ${ }^{18}$ analyzed 180 medical records of patients aged 5 to 16 years, evaluated between March, 2010 and December, 2014 , in a speech-language-hearing clinic. The domains of the ICF-CY were used to classify this population. The classification according to the ICF domains enabled the identification of existing speech-language-hearing aspects which affected functional performance and quality of life in children and youth.

With the methodology used, only one study involving knowledge of dysphagia and the ICF ${ }^{19}$; however, since it was a review of literature, it didn't meet the inclusion criteria for this review.

In face of the analyzed studies, the ICF may be used as a tool for identifying the functioning and participation of patients with speech-language-hearing disorders, and for tracing the therapy's progress, including the professional's, the patient's and the relatives' perception.

It has been noticed an unequal distribution of studies in the various fields of knowledge in speechlanguage-hearing, which may be justified by certain speech-language-hearing disorders being commonly associated with neurologic and oncologic alterations, in which prevails the use of the International Classification of Diseases (ICD-10).

In the past two years there has been an increase in publications on this theme, which may be related to the new version of the ICF, published in 2015, encompassing specific domains for children, youth and adults. The rehabilitation professionals have been the protagonists in using and producing knowledge related 
to the ICF, and some studies are being published aiming at guiding professional centers on how to make a diagnosis or how to plan the therapy in an ICF-based, multiprofessional way ${ }^{20}$.

Even though recent studies are known to have been presented in congresses, as well as dissertations and theses have been defended, regarding the use of ICF in speech-language-hearing, these were not considered in this article because they hadn't been published.

In spite of the importance of the ICF, the scarce use of the tool registered in speech-language-hearing literature may be associated to the complexity of its application and to the lack of knowledge of the health professionals ${ }^{21}$.

\section{CONCLUSION}

This integrative review has identified the speechlanguage-hearing's initial look at the ICF regarding therapeutic practice. It has been shown that, of the nine analyzed studies, the speech-language-hearing field with most correlation with ICF was that of language ( $\mathrm{n}$ $=6$ ), with a need of further exploring about the subject, especially in the fields of voice, dysphagia, orofacial motor control, and schooling.

After this analysis, it is possible to state that the ICF can contribute to guiding speech-languagehearing rehabilitation, towards a rehabilitation process that considers the professionals', patients' and their relatives' perception, as well as furnishing the means for developing unique therapeutic projects.

\section{ACKNOWLEDGEMENT}

The present study was carried out with support from the Coordination for the Improvement of Higher Education Personnel - Brazil (CAPES, as abbreviated in Portuguese).

\section{REFERENCES}

1. Castaneda L, Bergmann A, Bahia L. The International Classification of Functioning disability and health: a systematic review of observational studies. Rev Bras Epidemiol. 2014;17(2):437-51.

2. Organização Mundial de Saúde (OMS). CIF: Classificação Internacional de Funcionalidade, Incapacidade e Saúde. São Paulo: Edusp; 2015.

3. Santos SSC, Lopes MJ, Vidal ADS, Gautério DP. Classificação Internacional de Funcionalidade, Incapacidade e Saúde: utilização no cuidado de enfermagem a pessoas idosas. Rev Bras Enferm. 2013;66(5):789-93.

4. Araujo ES, Buchalla CM. O uso da Classificação Internacional de Funcionalidade, Incapacidade e Saúde em inquéritos de saúde: uma reflexão sobre limites e possibilidades. Rev Bras Epidemiol. 2015;18(3):720-4.

5. World Health Organization (WHO). Relatório mundial sobre a deficiência. In: The World Bank. Trad Lexicus Serviços Linguísticos. São Paulo: SEDPcD; 2012.

6. Farias N, Buchalla CM. A Classificação Internacional de Funcionalidade, Incapacidade e Saúde da Organização Mundial da Saúde: conceitos, usos e perspectivas. Rev. bras. epidemiol. 2005;8(2):187-93.

7. Romano N, Chun RYS. Condições linguísticocognitivas de crianças usuárias de comunicação suplementar e/ou alternativa segundo componentes da CIF. Distúrb. Comun. 2014;26(3):503-18.

8. Pernambuco AP, Lana RC, Polese JC. Knowledge and use of the ICF in clinical practice by physiotherapists and occupational therapists of Minas Gerais. Fisioter Pesqui.2018;25(2):134-42.

9. Lima TG, Barbosa P, Modesto GP, Valduga R. O uso da CIF para caracterização da funcionalidade de pacientes críticos em uma unidade de emergência. XXVII Fórum Nacional de Ensino em Fisioterapia e IV Congresso Brasileiro de Educação em Fisioterapia; João Pessoa; Rede Unida; 2017.

10. Alexandrino K, Dutra MB, Souza IN, Amorin J, Castaneda L. Utilização e conhecimento da Classificação Internacional de Funcionalidade, Incapacidade e Saúde (CIF) por fisioterapeutas brasileiros. XXVIII Fórum Nacional de Ensino em Fisioterapia, $V$ Congresso Brasileiro de Educação em Fisioterapia; Vitória; Unida; 2018.

11. Thomas-Stonell N, Oddson B, Robertson B, Rosenbaum P. Predicted and observed outcomes in preschool children following speech and language treatment: parent and clinician perspectives. J Commun Disord. 2009;42(1):29-42.

12. Stocks R, Dacakis G, Phyland D, Rose M. The effect of smooth speech on the speech production of an individual with ataxic dysarthria. Brain Injury. 2009;23(10):820-9.

13. Pommerehn J, Delboni MCCC, Fedosse E. International Classification of Functioning, Disability and Health, and aphasia: a study of social participation. CoDAS. 2016;28(2):132-40. 
14. Ostroschi DT, Zanolli ML, Chun RYS. Families' perception of children / adolescents with language impairment through the International Classification of Functioning, Disability, and Health (ICF-CY). CoDAS. 2017;29(3):e20160096.

15. Santana MTM, Chun RYS. Language and functionality of post-stroke adults: evaluation based on International Classification of Functioning, Disability and Health (ICF). CoDAS. 2017;29(1):e20150284.

16. Morettin M, Cardoso MRA, Delamura AM, Amantini $\mathrm{RCB}$, Bevilacqua MC. Use of the International Classification of Functioning, Disability and Health for monitoring patients using cochlear implants. CoDAS. 2013;25(3):216-23.

17. Bernardi AS, Alvarenga S, Pupo AC, Trenche MCB. The use of ICF in the monitoring of hearing and language development in children in their first year of life. Rev. CEFAC. 2017;19(2):159-70.

18. Borges MGS, Medeiros AM, Lemos SMA. Characterization of communication disorders according to the categories of the International Classification of Functioning, Disability and Health - Children and Youth (ICF-CY). CoDAS. 2018;30(4):e20170184.

19. Jaramillo JH, Duque LMR, Patiño MCG, Gutiérrez MFS. Prognosis factors of dysphagia after stroke: a search and systematic Review. Rev. cienc. Salud. 2017;15(1):7-21.

20. Tordoya EJJ. Guía metodológica para elaborar el diagnóstico fisioterapéutico según la Clasificación Internacional del Funcionamiento (CIF), de la Discapacidad y de la Salud. Gaceta Médica Boliviana. 2016;39(1):46-52.

21. Andrade LEL, Oliveira NPD, Ruaro JA, Barbosa IRB, Dantas DS. Evaluation of the level of knowledge and applicability of the International Classification of Functioning, Disability and Health. Saúde Debate. 2017;41(114):812-23. 